\title{
A Review about Thermal Comfort in Aircraft
}

\section{FAN Juli", ZHOU Qiongyao}

Nanjing University of Aeronautics and Astronautics, Nanjing 210016, China

(C) Science Press, Institute of Engineering Thermophysics, CAS and Springer-Verlag GmbH Germany, part of Springer Nature 2018

\begin{abstract}
Thermal comfort is an important factor which affects both work efficiency and life quality. On the basis of satisfying the normal life of the crew and reliable work of equipment, the thermal comfort is increasingly pursued through the design of the environmental control system of modern craft. Thus, a comprehensive survey of the thermal comfort in the cockpit is carried out. First of all, factors affecting the thermal comfort in aircraft cabin are summarized, including low relative humidity, mean radiant temperature, colored light, human metabolic rate and gender, among which the first three factors are environmental factors and the other two are human factors. Although noise is not a factor affecting thermal comfort, it is an important factor in the overall satisfaction of the aircraft cabin environment. Then the thermal comfort prediction models are introduced, including thermal comfort models suitable for steady state uniform environment and thermal comfort models suitable for transient non-uniform environment. Then the limitations of the typical thermal comfort models applied to aircraft are discussed. Since the concept of thermal adaptation has been gradually accepted in recent years, many field studies on thermal adaptation have been carried out. Therefore, the adaptive thermal comfort models are summarized and analyzed systematically in this paper. At present, mixing ventilation (MV) system is widely used in most commercial aircraft. However, the air quality under the MV system is very poor, and contaminants cannot be effectively eliminated. So a noticeable shift is the design of ventilation system for cabin drawing lessons from the surface buildings. Currently, the most interesting question is that whether the traditional mixing ventilation (MV) system in an aircraft can be replaced by or combined with displacement ventilation (DV) system without decreasing thermal comfort. A reduction of energy consumption is a valuable gain. Additionally, various seat personalized ventilation systems have also been proposed which could effectively reduce the risk of infectious diseases. At present, optimal design of airflow in aircraft cabin is the most commonly used method to enhance thermal comfort and save energy. The optimal design of the aircraft cabin colored lighting system, however, is also worth trying.
\end{abstract}

Keywords: aircraft, thermal comfort, energy efficient, ventilation system, numerical simulation

\section{Introduction}

Thermal comfort is the thinking activity that the human body is satisfied with the surrounding thermal environment. Researches have shown that high-quality indoor environment can make people feel comfortable so that they can work efficiently $[1,2]$. In addition, the comfort of indoor thermal environment also greatly affects people's health. According to the survey, thermal comfort is linear with human health and work efficiency [3]. 
With the rapid development of Aeronautics and Space undertakings, more and more attention has been paid to thermal comfort in aircraft. However, the environment in the cabin is very different from the surface building environment [4-6]. The typical characteristics of cabin environment are low pressure, low humidity, lack of fresh air and high leak proofness. Each passenger has an average of only 1 to $2 \mathrm{~m}^{3}$ of space [7], which is far less than the general office environment. The cruising height of a commercial airliner is usually between $5490 \mathrm{~m}$ and $12500 \mathrm{~m}$ [8]. At this height, especially at higher altitudes, the moisture content of the atmosphere is very low. The moisture in the cabin mainly comes from passengers' perspiration evaporation, so the relative humidity in the cabin is usually less than $20 \%$ [9]. This low relative humidity can cause dry eyes, respiratory tract obstruction and other symptoms of discomfort $[10,11]$. A large number of recent studies have shown that the personalized air supply system in the cabin can effectively improve the air quality around the passengers and effectively reduce the pollutants in the passenger respiratory zone [12-15].

At present, there are many related researches and literature reviews on the thermal comfort of indoor environment in ground buildings [16-18], but few researches have been made on the thermal comfort in aircraft cabin environment. This work therefore is an attempt to summarize works in the field of human thermal comfort, as related to researches on thermal comfort of aircraft cabin. In the second section, the influencing factors of thermal comfort in aircraft cabin are discussed, and the recent research progresses are introduced from two aspects: environmental factors and human factors. In the third section, the thermal sensation prediction models are introduced from two aspects: the typical thermal sensation models under uniform, steady-state environment, and the new thermal sensation models under non-uniform, transient environment. In the fourth section, the research progress of adaptive thermal comfort is introduced. In the fifth section, the research progress and prospect of thermal comfort of aircraft cabin are introduced, which mainly focus on the development of the ventilation in aircraft cabin.

\section{Factors Affecting Thermal Comfort in Aircraft Cabin}

Whether in the living environment or working environment, people are constantly carrying out heat exchange with the surrounding environment, including heat convection, radiation heat transfer and heat conduction. It can be seen that the thermal comfort of human body is a feeling acquired through the combination of the thermal balance and the environment around the human body. It is the interaction of physiology and psychology. Therefore, the factors that affect human thermal comfort are environmental factors and human factors as shown in Figure 1.

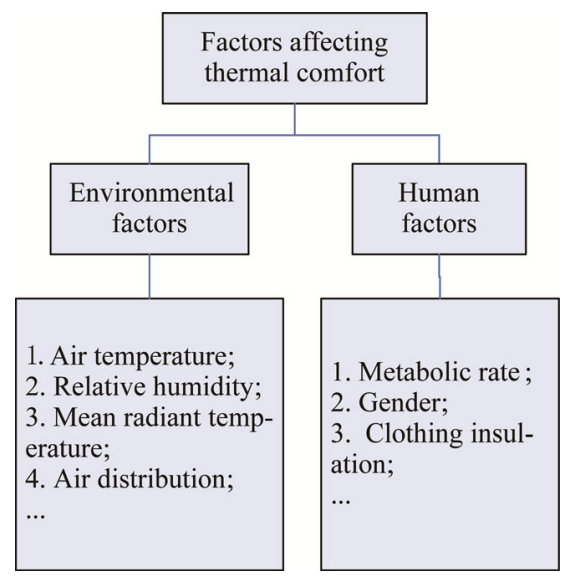

Fig. 1 Factors affecting thermal comfort

For the building environment, indoor climate is mainly determined by the temperature, air movement and humidity. Among these environment parameters, temperature is a crucial parameter for climate sensations. Thus various researches about environment parameters are mainly focused on temperature owing to temperature's important effect on working efficiency [19-21]. Compared to the situation when the air temperature was equal to the neutral temperature, when providing personal temperature control of $\pm 3^{\circ} \mathrm{C}$, whether it was mental work or complex physical work, the work efficiency was increased by $3 \%$, while simple tasks like typing could be increased by $7 \%$ [22]. More importantly, recent study on aircraft cabin thermal comfort also shows that air temperature has the greatest impact on thermal comfort compared to wind speed and relative humidity [23].

Airflow also plays an important role in improving indoor comfort. For example, in a higher temperature environment, increasing the airflow speed can compensate for the increase of temperature and humidity [24], improve air quality evaluation [25], and ensure work efficiency [26]. The influence of airflow velocity on thermal comfort is also affected by other factors such as radiation asymmetry, air temperature and activity level $[27,28]$. At higher levels of activity, improving the wind speed in a high temperature environment can ensure the thermal comfort of human body.

However, the factors shown in Figure 1 are generally specific to the building environment, and the aircraft cabin environment is more complex than the building environment. Therefore, in addition to the air temperature and airflow described above, the present work will introduce the factors affecting the thermal comfort of passengers in aircraft: low relative humidity, mean radiant temperature, colored light, human metabolic rate 
and gender, among which the first three factors are environmental factors and the other two are human factors.

\subsection{Environmental factors}

(1) Low relative humidity

In 1923, the study of relative humidity on thermal comfort was carried out by Houghtenhe and Yaglou for the first time. The thermal response of human body under different temperature $\left(T_{\mathrm{a}}\right)$ and relative humidity $(\mathrm{RH})$ was studied experimentally, and effective temperature (ET) was obtained [29]. Then, a large number of studies showed that when the temperature was within the comfort temperature range, the air humidity had no effect on the thermal comfort of human body [30,31]. Other factors were added in later studies, such as exercise intensity, metabolic rates, environmental temperature, wind speed and so on [32-34]. Mcnall et al. [35] investigated the effects of air relative humidity on thermal comfort at different metabolic rates. The research showed that: (1) The relative humidity had little influence on the thermal comfort of human body when the metabolic rates were low; (2) With the increase of metabolic rates, the influence of relative humidity on human thermal comfort was also enhanced. On this basis, the influence of air relative humidity on thermal comfort in different human activities was studied by Fountain et al. [36]. As the metabolism rate of human body is mainly affected by the intensity of human activities, the results of Fountain and Mcnall are basically the same. Thus only when relative humidity is combined with other parameters (such as wind speed, metabolism rate, etc.), it then could affect the thermal comfort of human body dramatically.

The cruising height of a commercial airliner is between 5490-12500 $\mathrm{m}$ [8]. The air pressure in the cabin is relatively low, which is generally equivalent to the atmospheric pressure at 1676-2134 $\mathrm{m}$ height (about 77.8 $\mathrm{kPa}-82.2 \mathrm{kPa}$ ) [9] and is much lower than the standard atmospheric pressure. At this height, especially at higher altitudes, the water content in the atmosphere is very little. The moisture in the cabin mainly comes from passengers' perspiration evaporation, so the relative humidity in the cabin is usually less than $20 \%$ [9]. Besides, the above researches on relative humidity are all based on indoor environment. The findings of these studies may not be fully applicable to aircraft cabin environments. Thus, some scholars have studied the effect of low relative humidity on the thermal comfort of passengers in the cockpit environment by means of experiment or field investigation.

In 2012, Grün et al. [37] studied the effects of low relative humidity by means of experimental study, which were performed in a simulated aircraft environment at the Fraunhofer Flight Test Facility (FTF). In order to give the subjects a real flight environment, the main environmental parameters in the cockpit were controlled, such as air pressure, air, fuselage temperature, relative humidity, background noise, ventilation rate and so on. In the experiment, 40 subjects experienced relative humidities of $10 \% \sim 40 \%$ at a temperature range of $21^{\circ} \mathrm{C} \sim 25^{\circ} \mathrm{C}$ and atmospheric pressures between $753 \mathrm{hPa}$ and ambient conditions $(\sim 940 \mathrm{hPa})$. The time of each experiment was 8 hours, in which the aircraft cruising phase was simulated in 7 hours. During the experiment, the subjects' evaluations and sensations were investigated to the including the sensation vote $(\mathrm{SV})$, comfort vote $(\mathrm{CV})$ as well as perceived symptoms of dry eye, nose, throat and skin. The results showed that: (1) High percentages of persons voting the environment as dry or reporting symptoms of dryness were found in a simulated aircraft cabin environment at relative humidities between $10 \%$ and $40 \%$; (2) Although there was a trend of decreasing dissatisfaction with increasing relative humidity, the direct relationships between perceived symptoms related to dryness as well as subjective assessment of dryness and relative humidity below $40 \%$ could not be drawn.

In 2014, Cui et al. [38] measured the thermal environmental parameters of 10 airlines (one international airline and nine domestic airlines), including 23 airplanes and 6 different types of aircraft. The measured thermal environmental parameters were air temperature, relative humidity, wall temperature, radiation temperature, wind speed, noise, light and absolute pressure. The questionnaires collected basic information of passengers (such as age, height, weight, and clothes level), and their evaluations of the environment including thermal comfort, perceived air quality, and symptoms. Cruise time ranged from 35 minutes to 510 minutes. The study showed that the average humidity in the cockpit was $26.3 \%$ and more than $15 \%$ of the passengers reported sleepiness and symptoms associated with humidity (such as dry eyes, nose and throat).

The findings of the above studies on low relative humidity show that: (1) Low relative humidity can cause dry eyes, respiratory tract obstruction and other symptoms of discomfort. However, the relationships between relative humidity and thermal sensation, thermal comfort, and related sensory symptoms cannot be directly expressed. (2) Comparing the findings of Gunnar et al. [37] and Cui et al. [38], only about $15 \%$ of the passengers reported dry eye, dry nose and other symptoms during the actual survey, which may be related to the length of flight. When flying time is short, the effect of low relative humidity on human body is not obvious, but as cruise time increases, passengers will feel more uncomfortable.

\section{(2) Mean radiant temperature}

The research suggests that the thermal convection of human body accounts for about 32\% 35\% of total heat dissipation, and evaporative heat accounts for about $20 \% \sim 25 \%$ of total heat dissipation, while the heat 
emitted by radiation accounts for about 42\% 44\% [39]. Mean radiant temperature is the average value of surface temperatures for radiation heat transfer with the human body in the environment. Thus, it has a great influence on thermal comfort of human body as well. The influence of cold radiation of exterior window on thermal comfort of human body has been studied by Wang et al. [40], He and Wang [41]. Researches showed that cold radiation from outside the window reduced the skin temperature of the body, especially the legs and the back skin temperature, thereby affecting the human thermal sensation and thermal comfort.

The influence of solar radiation on the thermal environment with large window area should not be ignored, especially the cockpit of an aircraft or a car. Moon et al. [42] studied the thermal comfort in the vehicle considering the solar spectral radiation by CFD, meanwhile, PMV-PPD model and equivalent temperature model were adopted to evaluate thermal comfort. The results showed that when the solar radiation was considered, the temperature around driver and passengers enhanced $1{ }^{\circ} \mathrm{C}-2^{\circ} \mathrm{C}$, and this slight temperature rise leaded to substantial changes in the passenger cabin thermal comfort. For cockpits with large glass windshields, the radiation heat load causing by solar radiation accounted for about $19.6 \%$ of the total heat load. Therefore, solar radiation has a crucial impact on the thermal comfort of human body inside the cockpit [43]. Zhi et al. [44] revised the radiation heat transfer term in the Predicted Mean Vote (PMV), and proposed a new thermal comfort evaluation index (PMV_F) for aircraft cockpit.

(3) Colored light

Colored light greatly influences people psychologically and physiologically. The effects of colored light have been studied in various situations, for instance, its impact on medical and/or therapeutic treatment, on work performance and/or job satisfaction, on learning efficacy, on purchasing behaviors and so on [45-47]. The light source will produce heat when lighting indoors, and will have certain influence on the thermal comfort of the human body. Changes in the color of lights can cause differences in people's psychological perception of the thermal environment. Bennett and Rey proposed "hueheat hypothesis" [48]. This hypothesis claims that 'cold' hues lead to the perception of cooler temperatures, while 'warm' hues lead to the perception of higher temperatures. Fanger et al. [49] also demonstrated that at an objectively equal room temperature, red light led to the perception of higher temperatures, whereas blue light created the perception of colder temperatures. The study by Winzen et al. [50] found that room temperature was perceived as being different depending on the color of the lighting. In yellow light, room temperature was felt to be warmer than in blue light. While, in blue light, subjects perceived better air quality and felt more alert.
The aim of Albers's study was to analyze the influence of colored light in an aircraft cabin on the thermal sensations and evaluations of passengers [51]. The findings indicated that the color of lighting was an objective factor that had an influence on subjective wellbeing, especially for susceptible people. Additionally, results of this study showed an effect in the hypothesized direction which was summarized by Bennett and Rey [48]. Based on this, some researchers [51,52] suggested that, in the aircraft cabin, colored lights could be used in such a way, that the passengers' thermal comfort and satisfaction could be promoted depending upon their needs, by changing the color of lights to make them seem warmer or cooler. A large scale application of this effect in the aircraft/ aviation industry could lead to energy savings and contribute to cost effectiveness.

\subsection{Human Factors}

The main human factors affecting human thermal comfort are clothing, activities, age, gender and so on [53]. The thermal comfort questionnaire and indoor thermal environment were tested and analyzed by Karyono [54] at Jakarta. Totally 596 staff members participated in the questionnaire survey. The research demonstrated that all these factors affect the thermal comfort. Specially, Human metabolism, gender, and clothing insulation have been the focus of researches in recent years. The present work, however, mainly introduced metabolic rate and gender.

(1) Human metabolism (metabolic rate)

It is necessary to determine the metabolic rate because it is one of the basic parameters of thermal comfort prediction. The metabolic rate is always regarded as constant value with changes in activity level. However, other factors, such as temperature, pressure and clothing insulation affecting the metabolic rate are usually ignored.

In fact, some researchers have begun to study on the influence factors of metabolic rate. The studies show that the metabolic rate is not only affected by the level of activity, but also by clothing, ambient temperature and pressure. Warwick and Busby [55] found that clothing (Subjects were allowed to adjust the clothes to keep the thermal comfort condition) could reduce the influence of cold on human energy consumption to some extent. Hoping to use a simple way to express the trend of metabolic rate, Luo et al. [56] studied the relationship between metabolic rate, environmental temperature and clothing insulation by experiment. In the experiment, air temperatures ranged from neutral $\left(26^{\circ} \mathrm{C}\right)$ to cold $\left(24 / 21 / 18 / 16^{\circ} \mathrm{C}\right)$ and to hot $\left(31 / 28^{\circ} \mathrm{C}\right)$, and clothing insulation were 0.42 clo and 0.91 clo. Wang [57] studied the effect of air temperature and pressure on human metabolic rate. The metabolic rate under four different pressure levels ( $1 \mathrm{~atm}, 0.95 \mathrm{~atm}, 0.9 \mathrm{~atm}, 0.8 \mathrm{~atm}$ ) and three different air temperature levels $\left(22^{\circ} \mathrm{C}, 25^{\circ} \mathrm{C}, 28^{\circ} \mathrm{C}\right)$ 
were measured. Cui et al. [58] studied the effect of low pressure environment on human metabolic rate. The metabolic rate under three different pressure levels (101 $\mathrm{kPa}, 85 \mathrm{kPa}, 70 \mathrm{kPa}$ ) was measured. The fitting formulas between the metabolic rate and its influencing factors are shown in Table 1 , where $M$ is metabolic rate, $v$ is air velocity, $R H$ is relative air humidity, $t_{a}$ is air temperature, and $P a$ is pressure. As shown in Table 1, human body metabolic rate is significantly influenced by thermal conditions. The trend of the metabolic rate could be expressed as two order polynomial equation associated with air temperature. Clothing insulation also significantly affects the variation trend of metabolic rate with temperature. Besides, there is a linear relationship between metabolic rate and pressure, however, the different air temperature and clothing insulation will make the coefficients different.

The formulas can be used to correct Fanger's PMV or Gagge's 2-Node model in low pressure conditions, which would make the prediction of thermal comfort under low-pressure environment more accurate.

(2) Gender

The difference of thermal comfort caused by gender differences is one of the research highlights. But different experimental conditions produce different results. An experimental study about gender difference for Chinese people was carried out by Lan et al. [59]. During the experiment, subjective questionnaire surveys were conducted, including thermal sensation votes, thermal comfort votes, draft sensations and so on. In addition, physiological parameters of human body were measured, including skin temperature (17 point) and heart rate variability (HRV). The experimental results show that: (1) Women are more sensitive to ambient temperature than men, but less sensitive to relative humidity; (2) Because the skin temperature of women is lower than that of men, women prefer neutral or slightly warmer environments, while men prefer neutral or cooler environments; (3) The comfortable operating temperature for women $\left(26.3^{\circ} \mathrm{C}\right)$ is slightly higher than that for men $\left(25.3^{\circ} \mathrm{C}\right)$. The research of Schellen et al. [60] showed that, in non-uniform environment, compared with men, the uncomfortable feeling of women in the thermal environment is stronger; and for women, local thermal sensation and limb skin temperature have significant effects on the overall thermal sensation. So in the non-uniform environment it is important to consider women's local thermal sensation, especially the limbs. An exploratory research on gender differences in human thermal reaction under the condition of personalized air nozzle was carried out by Wang [61]. Both subjective vote and objective physiological parameters were recorded. The study showed that females preferred neutral and little warm environment, while males preferred neutral and little cold environment, and there was a tendency that little cold and little warm thermal sensation may cause a stronger feeling of thermal discomfort for females compared to males; and when overall thermal sensation in the little cold side, the air sensation for females was stronger compared to males, while when overall thermal sensation in the little hot side, there was no significant difference of air sensation between men and women.

\subsection{Discussion}

There is no doubt that temperature and wind speed affect the thermal comfort of the passengers in the cockpit. In view of the particularity of the cabin environment, this paper expounds the influence of other factors on thermal comfort in aircraft cabin, including low humidity, colored light, mean radiant temperature, metabolic rate and gender. Noise, however, is another important environmental feature of aircraft cabin. Although noise is not a factor affecting thermal comfort, noise is an important factor in the overall satisfaction of the cabin environment. Overall satisfaction usually includes the evaluation of thermal comfort, sound comfort, air quality, etc. Some studies have shown that noise has the largest impact on overall satisfaction of all factors [62-65]. So the influence of noise on human beings' comfort should not be ignored.

Table 1 The fitting formulas between the metabolic rate and its influencing factors

\begin{tabular}{|c|c|c|c|}
\hline Reference & Affecting factors & Other conditions & Fitting formula \\
\hline \multirow{2}{*}{ Luo et al. [56] } & \multirow{2}{*}{ Air Temperature $\left(t_{\mathrm{a}},{ }^{\circ} \mathrm{C}\right)$} & \multirow{2}{*}{$\begin{array}{l}v \text { is } 0.1 \mathrm{~m} / \mathrm{s} \\
R H \text { is } 50 \%\end{array}$} & $M=0.07 t_{a}^{2}-4.03 t_{a}+116.07(0.42 \mathrm{clo})$ \\
\hline & & & $M=0.04 t_{a}^{2}-1.96 t_{a}+86.42(0.91 \mathrm{clo})$ \\
\hline Wang [57] & Air Temperature $\left(t_{\mathrm{a}},{ }^{\circ} \mathrm{C}\right)$ & $\begin{array}{c}v \text { is } 0 \pm 0.01 \mathrm{~m} / \mathrm{s} \\
R H \text { is } 69.7 \pm 4.3 \%\end{array}$ & $M=-0.022 t_{a}^{2}+1.09 t_{a}-12.75(0.36 \mathrm{clo})$ \\
\hline Cui et al. [58] & Pressure $(\mathrm{Pa}, \mathrm{kPa})$ & $\begin{array}{c}t_{\mathrm{a}} \text { is } 25^{\circ} \mathrm{C} \\
R H \text { is } 50 \%\end{array}$ & $M=-0.00509 P a+1.385(0.7 \mathrm{clo})$ \\
\hline \multirow{3}{*}{ Wang [57] } & \multirow{3}{*}{ Pressure $(\mathrm{Pa}, \mathrm{atm})$} & $\begin{array}{c}t_{\mathrm{a}} \text { is } 25^{\circ} \mathrm{C} \\
R H \text { is } 69.7 \pm 4.3 \%\end{array}$ & $M=-1.12 P a+2.2(0.36 \mathrm{clo})$ \\
\hline & & $\begin{array}{c}t_{\mathrm{a}} \text { is } 22^{\circ} \mathrm{C} \\
R H \text { is } 69.7 \pm 4.3 \%\end{array}$ & $M=-0.67 P a+1.5(0.36 \mathrm{clo})$ \\
\hline & & $\begin{array}{c}t_{\mathrm{a}} \text { is } 28^{\circ} \mathrm{C} \\
R H \text { is } 69.7 \pm 4.3 \% \\
\end{array}$ & $M=-1.35 P a+2.25(0.36 \mathrm{clo})$ \\
\hline
\end{tabular}




\section{Thermal Comfort Prediction Models}

\subsection{Typical thermal comfort models under uniform environment}

\subsubsection{Fanger's PMV model}

Based on the thermal balance of human body and thermal comfort equation, Fanger gained the predicted mean vote index (PMV) and predicted percentage of dissatisfied index (PPD) which has been widely used [31]. This model considers six different factors, including human activity intensity, clothing insulation, air temperature, mean radiant temperature, airflow rate and air humidity. The criteria for PMV are as shown in Table 2.

\subsubsection{Gagge's 2-Node model}

In 1971, Gagge proposed the 2-Node model [66]. The thermal comfort index corresponding to Gagge' s 2-Node model is SET* (Standard Effective Temperature) [67], which is based on ET* (New Effective Temperature) [66], and considers the influence of human activities, clothing insulation and skin wetness.

\subsubsection{Discussion on thermal comfort models}

Both of the two models are based on uniform, normal pressure, steady-state test data and although they work well under those conditions, they also have some limitations when applied to evaluate of thermal comfort of craft environment.

For common aircraft cabins, the interior is at a low pressure. Owing to changes of pressure, the mass transfer coefficient and the convective heat transfer coefficient between the human body and the surrounding environment alter correspondingly, which results in the change of heat dissipation characteristics of human body, such as the changes of convection and skin evaporation between the human body and environment [68]. At the same time, low air pressure results in lower air oxygen pressure, which will lead to the adjustment of respiratory function and finally lead to the change of heat dissipation through breathing. In addition, in low pressure environment, the metabolism of human body which is an important parameter in these two models will change.
The change of metabolic rate will seriously affect the accuracy of thermal comfort evaluation.

Therefore, according to the existing researches [57,69], these two models can be modified as follows:

(1) Modify metabolic rate according to pressure, and the modified equations are listed in Table 3;

(2) Modify evaporation heat transfer coefficient $\left(h_{\mathrm{e}}\right)$ according to pressure: $h_{e}=h_{e 0}\left(P / P_{0}\right)^{-0.45}$;

(3) Modify convection heat transfer coefficient $\left(h_{\mathrm{c}}\right)$ according to pressure: $h_{c}=h_{c 0}\left(P / P_{0}\right)^{0.55}$;

where $M$ is metabolic rate, $P$ is pressure, $M_{0}$ is the metabolic rate at the corresponding level of activity at the sea level, $P_{0}$ is atmospheric pressure at sea level, $h_{\mathrm{e} 0}$ and $h_{\mathrm{c} 0}$ is evaporation heat transfer coefficient and convection heat transfer coefficient at the sea level.

\subsection{Thermal comfort models under non-uniform and transient environment}

In fact, the environment in which people live is sometimes non-uniform and transient. For example, the use of task air conditioning (TAC) will result in a non-uniform environment; and the process of people walking from the hot outdoor to the air conditioning room is a transient environment. Therefore, more and more researches have focused on the prediction model of thermal sensation under non-uniform and transient environment. On the basis of literature investigation, different models are classified as follows:

(1) Models suitable for non-uniform environments

Teq [70] (Equivalent Temperature) and EHT [71] (Equivalent Homogeneous Temperature) are two very efficient evaluation indices for heterogeneous environments. However, it is necessary to solve the threedimensional flow field equation and the human biological heat equation when applying the two indexes.

The local thermal sensation affects the whole heat sensation, but the effect of different parts is different. Many studies [72-74] show that in cold environment, the local thermal sensations of chest, back and pelvis have the greatest influence on overall thermal sensation, and the local thermal sensation of the limbs has the least

Table 2 PMV's thermal sensation scale

\begin{tabular}{ccccccccc}
\hline Thermal Sensation & Hot & Warm & Slightly warm & Neutral & Slightly cool & Cool & Cold & -1 \\
\hline PMV & +3 & +2 & +1 & 0 & -2 & -3 & -2 \\
\hline
\end{tabular}

Table 3 The modified equations between the metabolic rate and pressure

\begin{tabular}{cccc}
\hline Reference & Affecting factors & Other conditions & Fitting formula \\
\hline Cui et al. [58] & Pressure $(P / \mathrm{kPa})$ & Sitting & $M=-0.00509 P+1.385$ \\
Wang [57] & Pressure $(P / \mathrm{atm})$ & Sitting & $M=M_{0}\left(P / P_{0}\right)^{-0.84}$ \\
& & Movement & $M=M_{0}\left(P / P_{0}\right)^{-0.76}$ \\
\hline
\end{tabular}




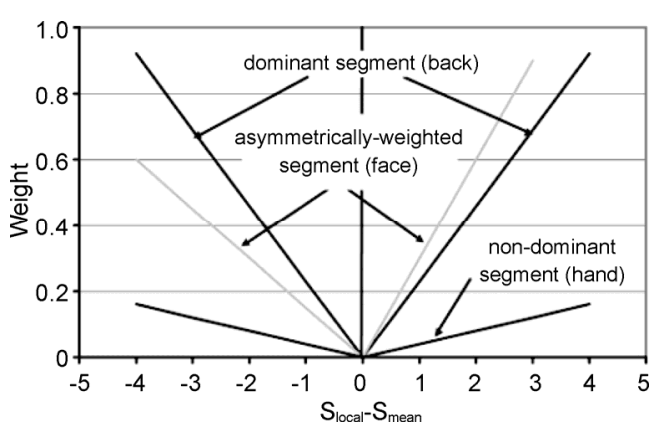

Fig. 2 Thermal sensation integration model showing three example segments [75], where $S_{\text {local }}$ is the local thermal sensation and $S_{\text {mean }}$ is the overall thermal sensation.

influence on the overall sensation. The study [75] shows that the influence factors of different parts increase linearly with the gap between the local thermal sensation and the overall thermal sensation. As shown in Figure 2, a dominant segment like back has a much higher weighting factor than a non-dominant segment such as hand. The face shows significant asymmetry between warm and cold sensations.

(2) Models suitable for transient environment:

Wang [76] proposed a thermal comfort model for both steady-state and transient conditions in 1994. Wang's model uses a static term from Fanger's model and a transient term based on the heat storage in the body. However, Wang's model is obtained for a specific comfort test condition, and when the transient conditions are different, the errors will appear.

Fialia [77] proposed a dynamic thermal sensation evaluation index (DTS), which was obtained by nonlinear analysis of skin temperature, mean skin temperature change rate, core temperature and thermal sensation votes. Fialia's model takes into account the effects of temperature (wind speed) gradient distribution, asymmetric radiation, solar radiation and other factors on the thermal response of human body.

(3) Models suitable for non-uniform and transient environment:

Zhang et al. [78-81] carried out a series of nonuniform and transient environmental experiments by means of local cooling or local heating. They found that both local skin temperature and overall thermal state would affect local thermal sensation. A local thermal sensation prediction model with local skin temperature, core temperature, average skin temperature and the change rate of skin temperature and core temperature is established by logistic function. The overall thermal sensation prediction model is a function of local thermal sensation.

Considering the difficulty of obtaining core temperature and the different thermal responses of people from different countries, Zhou et al. [82-84] established a local thermal sensation prediction model according to the physiological characteristics of Chinese people.

\section{Research Progress of Adaptive Thermal Comfort Model}

There are two main categories of thermal comfort models - Rational (RTC; [31]) and Adaptive (ATC; [85]). Study [86] has shown that when the indoor average temperature is between $21^{\circ} \mathrm{C}$ and $25^{\circ} \mathrm{C}$, it is quite effective to use PMV to predict people's thermal sensation. However, in the actual building without air-condition, or in the cold/hot environment, there is a big difference between the prediction of PMV model and people's actual thermal sensation. Moreover, the more the temperature deviates from the neutral temperature, the greater the deviation between PMV and actual thermal sensation, and the obvious "scissors difference" appears [87-89]. The main reason for the prediction error of PMV in hot or cold environment is that the standard based on artificial climate room neglects the subjective initiative of human and the interaction between human and environment, that is, the adaptability of human to thermal environment. Therefore, Nicol and Humphreys [90] put forward an adaptive thermal comfort model. The adaptive thermal comfort model is a strong linear relationship between the neutral temperature and the outdoor temperature index in natural ventilation buildings. The outdoor temperature index may vary from one model to other and some frequently used ones include monthly mean temperature, daily mean temperature, seven days running mean temperature, seven days average of mean temperatures, etc. Brager and de Dear [91] further developed the theory of thermal adaptation, and pointed out that thermal adaptation system included behavioral regulation, physiological adaptation and psychological adaptation. Therefore, the PMV model can predict the thermal comfort of people indoors, while adaptive thermal comfort model is designed to predict the neutral temperature. In addition, the adaptive thermal comfort model takes into account the dynamic characteristics of the natural environment, the interaction between people and the environment and local culture. Thus, the adaptive thermal comfort model based on a large amount of data from field investigation has attracted wide attention and interest.

Because of the differences in climate, culture, people's living habits, physiological characteristics and so on, the adaptive thermal comfort models are different in different regions. Table 4 gives a summary of adaptive thermal comfort models for foreign countries.

Chinese researchers have done a lot of studies on thermal adaption and adaptive thermal comfort model as 
well. In 2003, Yang [97] conducted thermal comfort field research and questionnaire survey on thermal comfort in five typical cities (Harbin, Beijing, Xi'an, Shanghai, Guangzhou) in China. A linear relationship between the neutral temperature $\left(T_{\mathrm{n}}\right)$ and the outdoor monthly mean temperature $\left(T_{\text {mout }}\right)$ for natural ventilation buildings in China was obtained: $T_{\mathrm{n}}=19.7+0.30 T_{\text {mout }}$. The relationship between outdoor ambient temperature and indoor neutral temperature in China was explained for the first time.

In 2007, a field study of student thermal comfort was conducted in the Chinese subtropics by Zhang et al. [98]. The thermal neutral temperature calculated by Thermal Sensation Vote $(T S V)$ was at about $21.5^{\circ} \mathrm{C}$. The relationship between actual thermal sensation vote (TSV) and operating temperature $\left(T_{\mathrm{op}}\right)$ is obtained: $T S V=$ $0.0448 T_{\text {op}^{-}} 0.9628$, however, the relationship is not strong (R2=0.37).

Additionally, the scholars have carried out abundant thermal adaption researches for different climate areas and different building types. Table 5 shows the adaptive thermal comfort models in China.

The following relevant conclusions can be drawn from Table 4 and Table 5:

(1) The adaptive thermal comfort models of different climatic regions are different. Climate has an important impact on human adaptation. People living in the tropics can better adapt to the hotter environment, and those who live in the frigid zone are more able to adapt to cold. Therefore, different types of outdoor climate will result in different adaptive abilities.

(2) Adaptive thermal comfort models for different seasons are also different. In different seasons, people adapt to the environment differently. In the spring, people can usually add or subtract clothes to make the body comfortable. But in the summer, when thermal comfort is not available by reducing clothing, people usually cool down by turning on fans, opening windows and other ways. Therefore, season is also a factor affecting the adaptive model.

(3) The type of building (naturally ventilated or air-conditioned) also has an effect on neutral temperature. When buildings use air conditioning in summer and can be heated in winter, the indoor neutral temperature is usually a constant.

(4) With different building functions (classroom, residence or office building), the adaptive thermal comfort model is different. For the study of classrooms and dormitories, the subjects are basically youth students. Whereas, in the study of housing, the subjects are ordinary residents. People of different ages have different adaptations to the environment, and young people are more adaptable than the elderly. Therefore, the age level of the subjects is also one of the factors affecting the adaptive thermal comfort model.

Table 4 A summary of adaptive thermal comfort models for foreign countries

\begin{tabular}{|c|c|c|c|c|c|}
\hline Investigators & $\begin{array}{l}\text { Architectural } \\
\text { type }\end{array}$ & Adaptive model & $\begin{array}{c}\text { Experiment } \\
\text { location }\end{array}$ & $\begin{array}{l}\text { number of } \\
\text { samples }\end{array}$ & $\begin{array}{l}\text { Experiment } \\
\text { time }\end{array}$ \\
\hline $\begin{array}{c}\text { de DEAR [92] } \\
\text { (ASHRAE } \\
\text { RP-884 Project) }\end{array}$ & 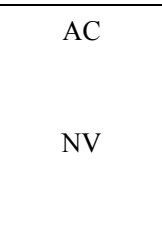 & $\begin{array}{l}T_{\mathrm{n}}=21.5+0.11 E T^{*}{ }_{\text {out }} \\
T_{\mathrm{n}}=18.9+0.26 E T^{*}{ }_{\text {out }}\end{array}$ & $\begin{array}{l}\text { Australia, } \\
\text { Canada, } \\
\text { Greece, } \\
\text { Indonesia, } \\
\text { Pakistan, } \\
\text { Singapore, } \\
\text { UK, USA }\end{array}$ & 21,000 & $\begin{array}{l}\text { Summer } \\
\text { Winter } \\
\text { Hot season } \\
\text { Dry season } \\
\text { Wet season }\end{array}$ \\
\hline $\begin{array}{c}\text { Nicol \& Roaf } \\
{[93]}\end{array}$ & $\mathrm{AC}$ & $T_{\mathrm{n}}=17.0+0.38 T_{\text {mout }}$ & Pakistan & 4927 & $\begin{array}{l}\text { Summer } \\
\text { winter }\end{array}$ \\
\hline $\begin{array}{l}\text { Toea \& Kubota } \\
\text { [94] (based on } \\
\text { ASHRAE } \\
\text { RP-884 } \\
\text { database) }\end{array}$ & $\mathrm{AC}, \mathrm{NV}$ & $\begin{array}{l}\text { Moderate: } T_{\mathrm{n}}=0.22 T_{\text {Dout }}+18.6 \\
\text { Hot and dry: } T_{\mathrm{n}}=0.58 T_{\text {Dout }}+13.7 \\
\text { Hot and humid: } T_{\mathrm{n}}=0.57 T_{\text {Dout }}+13.8\end{array}$ & l & / & / \\
\hline $\begin{array}{c}\text { Rijal et al. } \\
{[95]}\end{array}$ & $\begin{array}{l}\text { AC, NV } \\
\text { (Houses) }\end{array}$ & $\begin{array}{l}\text { For free running: } T_{\mathrm{n}}=0.453 T_{\mathrm{rm}}+15.0 \\
\text { In summer: } T_{\mathrm{n}}=0.188 T_{\mathrm{rm}}+21.9 \\
\text { In winter: } T_{\mathrm{n}}=0.178 T_{\mathrm{rm}}+18.8\end{array}$ & Japan & 32468 & $\begin{array}{c}\text { From } 2010 \text { to } \\
2013\end{array}$ \\
\hline $\begin{array}{c}\text { Singh et al. } \\
{[96]}\end{array}$ & $\begin{array}{c}\text { AC, NV } \\
\text { Vernacular } \\
\text { architecture }\end{array}$ & $\begin{array}{l}\text { Warm and humid climate: } \\
T_{\mathrm{n}}=22.69+0.15 T_{\text {Dout }} \\
\text { Cool and humid climate: } \\
T_{\mathrm{n}}=20.56+0.18 T_{\text {Dout }} \\
\text { Cold and cloudy climate: } \\
T_{\mathrm{n}}=17.76+0.22 T_{\text {Dout }}\end{array}$ & North-East India & $\begin{array}{c}150 \\
\text { households }\end{array}$ & $\begin{array}{l}\text { Summer } \\
\text { winter }\end{array}$ \\
\hline
\end{tabular}

$\mathrm{NV}$ : naturally ventilated; $\mathrm{AC}$ : air-conditioned (heating and cooling); $T_{\mathrm{n}}$ : neutral temperature $\left({ }^{\circ} \mathrm{C}\right) ; E T^{*}{ }_{\text {out: }}$ outdoor daily effective temperature $\left({ }^{\circ} \mathrm{C}\right)$; $T_{\text {mout }}$ : the mean outdoor temperature in the preceding month $\left({ }^{\circ} \mathrm{C}\right) ; T_{\mathrm{rm}}$ : the exponentially weighted running mean outdoor temperature for the day $\left({ }^{\circ} \mathrm{C}\right)$; $T_{\text {Dout }}: 24 \mathrm{~h}$ average outdoor temperature $\left({ }^{\circ} \mathrm{C}\right)$ 
Table 5 A summary of the adaptive thermal comfort models in China

\begin{tabular}{|c|c|c|c|c|c|}
\hline Investigators & Architectural type & Adaptive model & Experiment location & number of samples & Experiment time \\
\hline Mao [99] & House (AC, NV) & $\begin{array}{l}\text { Severe cold: } \\
T_{\mathrm{n}}=0.121 T_{\text {out }}+21.488 \\
\text { Cold: } \\
T_{\mathrm{n}}=0.271 T_{\text {out }}+20.014 \\
\text { Hot summer and cold winter: } \\
T_{\mathrm{n}}=0.326 T_{\text {out }}+16.862 \\
\text { Hot summer and warm winter: } \\
T_{\mathrm{n}}=0.554 T_{\text {out }}+10.578\end{array}$ & $\begin{array}{c}\text { Harbin, Changchun, } \\
\text { Shenyang } \\
\text { Beijing, Zhengzhou, } \\
\text { Xi'an } \\
\text { Nanjing, Chongqing, } \\
\text { Shanghai } \\
\text { Nanning, Guangzhou, } \\
\text { Haikou }\end{array}$ & $\begin{array}{l}30 \\
30\end{array}$ & $\begin{array}{l}\text { Summer } \\
\text { winter }\end{array}$ \\
\hline $\begin{array}{l}\text { Yang et al. } \\
\quad[100]\end{array}$ & House (NV) & $\begin{array}{l}\text { Moderate: } \\
T_{\mathrm{n}}=0.498 T_{\text {out }}+11.537\end{array}$ & Kunming & 228 & $\begin{array}{c}\text { Summer } \\
\text { winter }\end{array}$ \\
\hline Yang et al. & $\begin{array}{l}\text { Office buildings } \\
\text { (NV) }\end{array}$ & $T_{\mathrm{n}}=0.56 T_{\mathrm{rm}}+12.6$ & Changsha & unknown & $\begin{array}{l}\text { from Jan. } 2010 \text { to } \\
\text { Feb. } 2011\end{array}$ \\
\hline Cao [102] & $\begin{array}{l}\text { Classrooms } \\
(\mathrm{NV}, \mathrm{AC})\end{array}$ & $\begin{array}{l}\text { In spring: } \\
T_{\mathrm{n}}=0.18 T_{\text {out }}+21.64 \\
\text { In summer }(\mathrm{NV}): \\
T_{\mathrm{n}}=0.08 T_{\text {out }}+23.70 \\
\text { In summer }(\mathrm{AC}): \\
T_{\mathrm{n}}=25.4^{\circ} \mathrm{C} \text {; } \\
\text { In winter (Heating): } \\
T_{\mathrm{n}}=22.8^{\circ} \mathrm{C}\end{array}$ & Beijing & 1185 & $\begin{array}{l}\text { Spring } \\
\text { summer } \\
\text { winter }\end{array}$ \\
\hline $\mathrm{Yu}[103]$ & $\begin{array}{c}\text { House } \\
\text { Office buildings } \\
\text { Dormitories } \\
\text { Classrooms }\end{array}$ & $\begin{array}{l}\text { In winter (heating): } \\
T_{\mathrm{n}}=22.1^{\circ} \mathrm{C} \\
\text { In winter (heating): } \\
T_{\mathrm{n}}=21.5^{\circ} \mathrm{C} \\
\text { In winter (heating): } \\
T_{\mathrm{n}}=21.1^{\circ} \mathrm{C} \\
\text { In winter (heating): } \\
T_{\mathrm{n}}=19.1^{\circ} \mathrm{C}\end{array}$ & Harbin & 1747 & $\begin{array}{c}\text { From Oct. } 2013 \text { to } \\
\text { Apr. } 2014\end{array}$ \\
\hline
\end{tabular}

$T_{\text {out }}:$ the daily outdoor average temperature $\left({ }^{\circ} \mathrm{C}\right) ; T_{\mathrm{rm}}$ : the running mean outdoor temperature $\left({ }^{\circ} \mathrm{C}\right)$

\section{Research Progress of Thermal Comfort in Aircraft Cabin}

In the aircraft cabin, air distribution determines the temperature, relative humidity, air velocity and so on. Therefore, air distribution is an important content in the design of aircraft environmental control system (ECS). Effective ventilation and reasonable airflow organization are important for improving air quality, controlling pollutant level, saving energy and improving comfort. Thus this paper mainly focuses on the research status of airflow organization in aircraft cockpit.

The air conditioning system in airplane cockpit plays a vital role in providing passengers with a healthy, safe and comfortable environment. The mixing ventilation (MV) system is commonly used in commercial airplane. High velocity air flows from the ceiling side, and the polluted air is expelled from the outlet near the floor [104]. High speed mixing air not only affects air quality, comfort of human body, but also affects human health. Therefore, many scholars have studied the MV system and made corresponding improvements. On the other hand, due to the convenience and higher precision of CFD (computational fluid mechanics ), CFD technology has become an important way to study the flow field $[105,106]$, which plays an important role in the study of airliner cabin flow field as well. Numerical analysis of airflow can take into account various possible internal disturbances, boundary conditions and initial conditions, so it can reflect the distribution of the indoor airflow. Thus, it is easy to find the optimal air distribution, and then guide the design to achieve good ventilation. As a result, many aircraft cockpit thermal comfort studies as shown in Table 6, have been carried out with CFD and related commercial software.

A new type of MV system with four air inlets which are arranged on the side wall of the luggage rack and the top side wall of the cabin has been proposed by $\mathrm{Wu}$ [107] Compared with traditional MV systems with two air inlets and with three air inlets, during cruising time, the MV system with four air inlets can create the most comfortable thermal environment; the predicted mean vote index (PMV) is close to 0 and the Draft Rate (DR) is the lowest. Zhang [108] also used the CFD software to study two different MV systems (supplying air from ceiling, supplying air from both ceiling and side wall) in the cockpit, and the Gagge's 2-Node model was adopted in the study which was corrected according to the lowpressure environment in the cockpit.

Additionally, in order to improve the thermal comfort of the cockpit, some new ventilation systems have been proposed, such as displacement ventilation (DV) system and personalized ventilation (PV) system. DV system can remove pollutants more effectively than conventional airliner airflow [109]. Zhang and Chen [110] proposed the application of DV system in the cockpit. The air 
supply vent was located at the bottom of the corridor, while the air outlet was located at the top of the cabin. Compared with the MV system, the energy consumption of DV system is lower, and the implementation of DV system is beneficial to improve the energy efficiency of the aircraft [111]. However, one of the typical disadvantages of DV system is that it is easy to cause temperature stratification and cause thermal discomfort [112]. However, the study of Maier et al. [113] indicated that DV could provide a comfortable climate situation in the aircraft passenger cabin with low air velocities. Although the known disadvantages compared to MV were confirmed (e.g. vertical temperature differences or colder temperatures around the feet), these did not influence the subjects' satisfaction ratings very much. Another novel ventilation named as hybrid ventilation (HV) system as shown in Figure 3, can weaken the vertical temperature gradient as well as ensure high heat removal efficiency [114-116]. In fact, HV system is a combination system of MV system and DV system.

The PV system can supply fresh air directly to the passenger's breathing area and effectively eliminate the pollutants. Zhang and Chen [110] proposed the application of PV system in the cockpit. For the PV system, a personalized air supply vent was mounted at the rear of the passenger seat. The PV system can reduce the degree of air mixing and especially conducive to the discharge of pollutants around the passengers. Zítek et al. [13] proposed another PV system which considered the problem of humidifying cabin air. As shown in Figure 4, the personalized air supply vent was built into the back of the seat in front of the passenger, and an air exhaust nozzle was located just below the air supply vent. Li [117] also designed a new type of personalized seat ventilation system. As shown in Figure 5, the full fresh air supply vents were located at the armrest and the bottom of the individualized chair, and an air inlet for circulating air was located at the bottom of the seat. Whereas, the PV system could also create temperature stratification [118].

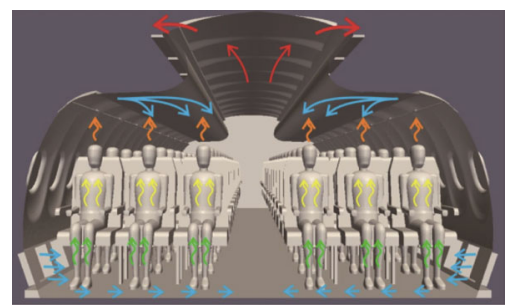

Fig. 3 Combination of DV and MV (HV system) [115]

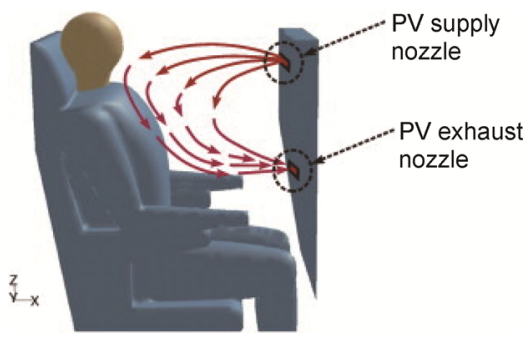

Fig. 4 Scheme and geometric model of the PV set-up of the seat [13]

On the basis of literature research, we find that most of the thermal comfort researches on aircraft cockpit are focused on small single channel airliner. However, in the future, wide-body airliner, is the key development direction of the future aircraft cockpit. The flow field in the wide-body airliner will be more complex, and how to optimize the air supply system in the wide-body airliner will also be the focus.

Table 6 Summary of investigation of flow field in aircraft cabin

\begin{tabular}{|c|c|c|c|c|c|c|}
\hline Reference & Aircraft cabin & $\begin{array}{l}\text { Research } \\
\text { contents }\end{array}$ & Research method & Process & $\begin{array}{l}\text { Thermal comfort } \\
\text { evaluation method }\end{array}$ & Other indicators \\
\hline $\mathrm{Wu}[107]$ & $\begin{array}{l}\text { Single passage } \\
\text { cabin }\end{array}$ & MV system & $\begin{array}{l}\text { Finite Volume Method } \\
\text { (Fluent) }\end{array}$ & $\begin{array}{l}\text { Warm up in } \\
\text { winter; steady }\end{array}$ & PMV & Draft (DR) \\
\hline $\begin{array}{l}\text { Zhang } \\
\text { [108] }\end{array}$ & $\begin{array}{l}\text { Single passage } \\
\text { cabin }\end{array}$ & MV system & $\begin{array}{l}\text { Finite Volume Method } \\
\text { (Fluent) }\end{array}$ & Steady & $\begin{array}{c}\text { Gagge's 2-Node } \\
\text { model; SET* }\end{array}$ & $\mathrm{CO}_{2}$ concentration \\
\hline $\begin{array}{l}\text { Zhang and } \\
\text { Chen [110] }\end{array}$ & $\begin{array}{l}\text { Boeing-767 } \\
\text { aircraft cabin }\end{array}$ & $\begin{array}{l}\text { MV, DV and } \\
\text { PV system }\end{array}$ & $\begin{array}{l}\text { Finite Volume Method } \\
\text { (Fluent) }\end{array}$ & Steady & Not accounted for & $\mathrm{CO}_{2}$ concentration \\
\hline $\begin{array}{l}\text { Bosbach } \\
\text { et al. [115] }\end{array}$ & $\begin{array}{l}\text { A320 aircraft } \\
\text { cabin }\end{array}$ & DV, HV system & Experimentation & $\begin{array}{l}\text { Steady and } \\
\text { dynamic } \\
\text { measurement }\end{array}$ & Not accounted for & $\begin{array}{l}\text { Heat removal } \\
\text { efficiency }\end{array}$ \\
\hline $\begin{array}{l}\text { Zhang } \\
\text { et al. [116] }\end{array}$ & $\begin{array}{c}\text { Boeing } \\
737-200 \\
\text { aircraft cabin }\end{array}$ & $\begin{array}{l}\text { MV, DV and } \\
\text { HV system }\end{array}$ & Experimentation & Steady & Not accounted for & $\begin{array}{l}\text { Mean age of air; } \\
\text { Velocity and temperature } \\
\text { non-uniformity indices; }\end{array}$ \\
\hline $\begin{array}{l}\text { Maier } \\
\text { et al. [113] }\end{array}$ & Do 728 cabin & $\begin{array}{l}\text { MV, DV and } \\
\text { HV system }\end{array}$ & Experimentation & Steady & $\begin{array}{c}\text { Thermal comfort } \\
\text { vote }\end{array}$ & $\begin{array}{l}\text { Means for air draught } \\
\text { perceptions; Means for } \\
\text { temperature perceptions }\end{array}$ \\
\hline $\begin{array}{c}\text { Zítek } \\
\text { et al. [13] }\end{array}$ & $\begin{array}{l}\text { Boeing-767 } \\
\text { aircraft cabin }\end{array}$ & $\begin{array}{l}\mathrm{PV} \text { and MV } \\
\text { system }\end{array}$ & $\begin{array}{c}\text { Finite Volume Method } \\
\text { (Fluent) } \\
\text { experimentation }\end{array}$ & Steady & Not accounted for & $\begin{array}{l}\text { Relative humidity } \\
\text { distribution }\end{array}$ \\
\hline $\operatorname{Li}[117]$ & $\begin{array}{l}\text { Single passage } \\
\text { cabin }\end{array}$ & $\begin{array}{l}\mathrm{PV} \text { and MV } \\
\text { system }\end{array}$ & $\begin{array}{l}\text { Finite Volume Method } \\
\text { (Fluent) }\end{array}$ & Steady & PMV, PPD & DR \\
\hline
\end{tabular}




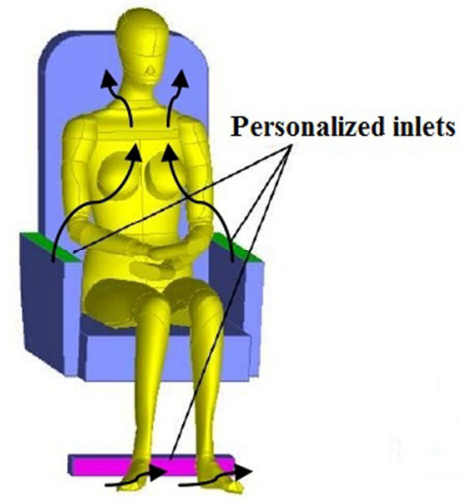

Fig. 5 Personalized inlets of the seat [117]

\section{Conclusions}

(1) There are many factors affecting the thermal comfort of human body in aircraft cabin, including low relative humidity, mean radiant temperature, colored light, human metabolic rate and gender, among which the first three factors are environmental factors and the other two are human factors. Additionally, different from indoor environment, low pressure and low relative humidity in aircraft cabin affect people's thermal comfort. Although noise is not a factor affecting thermal comfort, it is a typical feature of the aircraft environment. Besides, the most important influence factor of overall satisfaction in aircraft cabin is noise.

(2) Both of the Fanger's PMV model and Gagge's 2-Node model are based on uniform, normal pressure, steady-state test data. But there are great differences between craft environment and buildings on the ground. As a result, there is a pressing need to appropriately modify these models to make the simulation results more accurate in craft environment.

(3) The adaptive thermal comfort model takes into account the external environment, climate, human adaptability and so on, therefore, it can well reflect the thermal sensation in the natural ventilation building. But the adaptive thermal comfort model is based on field research and questionnaire survey, so experimental time, climatic characteristics, subject age, building function and so on will affect the regression coefficient and regression constant of the model. While the thermal comfort prediction models such as PMV, DTS, 2-Node model, are based on the thermal balance of human body, however, ignore the ability of the human body to adapt to the environment. These models have their own advantages and disadvantages, so the future research should consider the combination of adaptive thermal comfort models and other thermal comfort prediction models from the aspects of heat balance and human adaptability.

(4) With the improvement of living standards, thermal comfort study of aircraft attracts more and more attention. Due to the convenience and higher precision of CFD, CFD technology has become an important way of thermal comfort research in aircraft.

(5) The environment in aircraft cabin is usually nonuniform under DV system, PV system or individualized air supply system (such as nozzle air supply). In order to accurately describe the thermal sensation and thermal comfort of different body parts, the appropriate model should be selected, such as Teq or EHT. But in some special cases, the cabin environment is transient, such as the period of just opening a personalized air supply, the process of people walking from the hot outdoor to the aircraft cabin, or aircraft climbing phase. Whereas, Teq and EHT are only suitable for steady-state environment, so in such conditions Teq or EHT can't be used to evaluate thermal comfort of human beings any longer. At this time, it is recommended to use the thermal comfort prediction models which are suitable for transient environment.

(6) Compared with the traditional MV system, the DV system has higher ventilation efficiency and energy utilization efficiency, but it is easy to cause temperature stratification. A combination of MV system and DV system can weaken the vertical temperature gradient as well as ensure high heat removal efficiency. In addition, the application of displacement ventilation system in wide-body airliner remains to be further studied.

(7) This paper mainly introduces the method of achieving better thermal comfort in aircraft cabin by optimizing the airflow. In addition, it is also a new way to optimize the design of the aircraft cabin lighting system. Colored light can be used in conjunction with ECS to affect the thermal sensation of passengers. More specifically, colored light could be used in such a way, that passengers can change the color or brightness of the colored light depending upon their needs to make it seem warmer or cooler, thereby improving the passenger's happiness. However, the effects of color lights on thermal sensation are still in the stage of experimental and theoretical research. Therefore, the optimization of aircraft cabin lighting system needs further study.

\section{Acknowledgements}

Supported by the National Natural Science Foundation of China (51106074).

\section{References}

[1] Fisk W.J., How IEQ affects health, productivity. ASHRAE Journal, 2002, 44(5): 56-60.

[2] Yu J., Zhu Y., Ouyang Q., Discussion on research routes of using physiological index to evaluate human thermal 
comfort, work efficiency and long-term health. Heating Ventilating \& Air Conditioning, 2010, 40(03): 1-5.

[3] Leaman A., Bordass B., Assessing building performance in use 4: the Probe occupant surveys and their implications. Building Research \& Information, 2001, 29: 129-143.

[4] Haghighat F., Allard F., Megri A.C., et al., Measurement of thermal comfort and indoor air quality aboard 43 flights on commercial airlines. Indoor and Built Environment, 1999, 8(1): 58-66.

[5] Lindgren T., Norbäck D., Cabin air quality: indoor pollutants and climate during intercontinental flights with and without tobacco smoking. Indoor Air, 2002, 12: 263-272.

[6] Wang C., Yang X., Guan J., et al., Source apportionment of volatile organic compounds (VOCs) in aircraft cabins. Building \& Environment, 2014, 81: 1-6.

[7] Hocking M.B., Passenger aircraft cabin air quality: trends, effects, societal costs, proposals. Chemosphere, 2000, 41(4): 603-615.

[8] Spengler J.D., Ludwig S., Weker R.A., Ozone exposures during trans-continental and trans-Pacific flights. Indoor Air, 2004, 14: 67-73.

[9] Strøm-Tejsen P., Wyon D.P., Lagercrantz L., et al., Passenger evaluation of the optimum balance between fresh air supply and humidity from 7-h exposures in a simulated aircraft cabin. Indoor Air, 2007, 17: 92-108.

[10] Nagda N.L., Rector H.E., A critical review of reported air concentrations of organic compounds in aircraft cabins. Indoor Air, 2003, 13: 292-301.

[11] Lindgren T., Norbäck D., Health and perception of cabin air quality among Swedish commercial airline crew. Indoor Air, 2005, 15: 65-72.

[12] Zhang T.T., Li P., Wang S., A personal air distribution system with air terminals embedded in chair armrests on commercial airplanes. Building \& Environment, 2012, 47: 89-99.

[13] Zítek P., Vyhlídal T., Simeunović G., Nováková L., et al., Novel personalized and humidified air supply for airliner passengers. Building \& Environment, 2010, 45: 2345-2353.

[14] Olsen S.J., Chang H.L., Cheung T.Y.Y., et al., Transmission of the severe acute respiratory syndrome on aircraft. New England Journal of Medicine, 2003, 349(25): 2416-2422.

[15] Dygert R.K., Dang T.Q., Mitigation of cross-contamination in an aircraft cabin via localized exhaust. Building \& Environment, 2010, 45: 2015-2026.

[16] Roaf S., Nicol F., Humphreys M., et al., Twentieth century standards for thermal comfort: promoting high energy buildings. Architectural Science Review, 2010, 53(1): 65-77.

[17] Van H.J., Mazej M., Hensen J.L., Thermal comfort: research and practice. Frontiers in Bioscience, 2010, 15(4): 765-788.

[18] de Dear R.J., Akimoto T., Arens E.A., et al., Progress in thermal comfort research over the last twenty years. Indoor Air, 2013, 23(6): 442-461.

[19] Wyon D., Healthy buildings and their impact on productivity. 6th International Conference on Indoor Air Quality and Climate, Helsinki, Finland: Indoor Air, 1993, 93: 3-13.

[20] Cui W., Cao G., Park J.H., et al., Influence of indoor air temperature on human thermal comfort, motivation and performance. Building \& Environment, 2013, 68: 114122.

[21] Kekäläinen P., Niemelä R., Tuomainen M., et al., Effect of reduced summer indoor temperature on symptoms, perceived work environment and productivity in office work: An intervention study. Intelligent Buildings International, 2010, 2(4): 251-266.

[22] Wyon D., Individual microclimate control: Required range, probable benefits and current feasibility. 7th International Conference on Indoor Air Quality and Climate. Nagoya, Japan, 1996, 1: 1067-1072.

[23] Maier J., Marggraf-Micheel C., Weighting of climate parameters for the prediction of thermal comfort in an aircraft passenger cabin. Building \& Environment, 2015, 84: 214-220.

[24] Kubo H., Isoda N., Enomoto-Koshimizu H., Cooling effects of preferred air velocity in muggy conditions. Building \& Environment, 1997, 32: 211-218.

[25] Zhang H., Arens E., Pasut W., Air temperature thresholds for indoor comfort and perceived air quality. Building Research \& Information, 2011, 39(2): 134-144.

[26] Zhu Y., Ouyang Q., Cao B., et al., Dynamic thermal environment and thermal comfort. Indoor Air, 2015, 26: 125-137.

[27] Fobelets A., Subjective human response to low-level air currents and asymmetric radiation. ASHRAE Transactions, 1987, 93: 497-523.

[28] Zhai Y., Elsworth C., Arens E., et al., Using air movement for comfort during moderate exercise. Building \& Environment, 2015, 94(1): 344-352.

[29] Houghten F.C., Yaglou, C.P., Determining lines of equal comfort. ASHVE Transactions, 1923, 29: 163-176.

[30] Nevins R.G., Rohles F.H., Springer W., et al., A temperature-humidity chart for thermal comfort of seated persons. ASHRAE Transactions, 1966, 72: 283-291.

[31] Fanger P.O., Thermal comfort. McGraw-Hill, New York, 1972, pp. 1-15.

[32] Mcintyre D.A., Griffiths I.D., Subjective responses to atmospheric humidity. Environmental Research, 1975, 9(1): 66-75.

[33] Jing S., Li B., Tan M., et al., Impact of relative humidity on thermal comfort in a warm environment. Indoor \& 
Built Environment, 2013, 22(4): 598-607.

[34] Xu K.L., Effect of Low Air Humidity on Human Comfort Sensation., Chongqing University, Chongqing, China, 2016.

[35] Mcnall P.E., Jaax R.F.H., Nevins R.G., Thermal comfort conditions for three levels of activity. ASHRAE Transactions, 1967, 73: 1-3.

[36] Fountain M.E., Arens E., Xu T.E., et al., An investigation of thermal comfort at high humidities. Center for the Built Environment, 1999, 105: 94-103.

[37] Grün G., Trimmel M., Holm A., Low humidity in the aircraft cabin environment and its impact on well-being Results from a laboratory study. Building \& Environment, 2012, 47(47): 23-31.

[38] Cui W., Ouyang Q., Zhu Y., et al., Thermal Environment and Passengers' Comfort in Aircraft Cabin. Lecture Notes in Electrical Engineering, 2014, 261: 321-328.

[39] Bachki L., Hot Micro-Climate of the Room. Fu Z.C. Translated. China Architecture \& Building Press, Beijing, 1987, pp.12-16.

[40] Wang Z., He Y., Hou J., et al., Human skin temperature and thermal responses in asymmetrical cold radiation environments. Building \& Environment, 2013, 67: 217-223.

[41] He M., Wang Z., Effect of values of PMV/PPD caused by the change of mean radiation temperature which near window in winter. Journal of Xian University of Architecture \& Technology. 2014, 46: 388-392.

[42] Moon J.H., Jin W.L., Chan H.J., et al., Thermal comfort analysis in a passenger compartment considering the solar radiation effect. International Journal of Thermal Sciences, 2016, 107: 77-88.

[43] Wu D., Study on Thermal Comfort in Cabin. Nanjing University of Aeronautics and Astronautics, Nanjing, China, 2011. (in Chinese)

[44] Zhi S., Sun J., Ming Z., et al., Analysis of thermal comfort in aircraft cockpit based on the modified PMV index. Acta Aeronautica Et Astronautica Sinica. 2015, 36: 819-826.

[45] Küller R., Ballal S., Laike T., et al., The impact of light and colour on psychological mood: a cross-cultural study of indoor work environments. Ergonomics, 2006, 49(14): 1496-1507.

[46] Iskra-Golec I.M., Wazna A., Smith L., Effects of blueenriched light on the daily course of mood, sleepiness and light perception: A field experiment. Lighting Research \& Technology, 2012, 44(4): 506-513.

[47] Motamedzadeh M., Golmohammadi R., Kazemi R., et al., The effect of blue-enriched white light on cognitive performances and sleepiness of night-shift workers: A field study. Physiology \& Behavior, 2017, 177: 208-214.

[48] Bennett C.A., Rey P., What's so hot about red? Human Factors, 1972, 14(2): 149-154.
[49] Fanger P.O., Breum N.O., Jerking E., Can colour and noise influence man's thermal comfort? Ergonomics, 1977, 20(1): 11-18.

[50] Winzen J., Albers F., Marggraf-Micheel C., The influence of coloured light in the aircraft cabin on passenger thermal comfort. Lighting Research \& Technology, 2013, 59(46): 465-475.

[51] Albers F., Maier J., Marggraf-Micheel C., In search of evidence for the hue-heat hypothesis in aircraft cabin. Lighting Research \& Technology, 2014, 47(4): 483-494.

[52] Lu Y., Lin Y., Liu J., et al., The ergonomie research on aircraft cabin mood lighting. 13th China International Forum on Solid State Lighting (SSL China), Beijing, China, 2017: 123-126.

[53] Yin H., Wang L., Zhang Y. et al., Overview of main parameters affecting human thermal comfort and its determination. Contamination Control \& Air-Conditioning Technology, 2016, (1): 19-23.

[54] Karyono T.H., Report on thermal comfort and building energy studies in Jakarta-Indonesia. Building \& Environment, 2000, 35: 77-90.

[55] Warwick P.M., Busby R., Influence of mild cold on $24 \mathrm{~h}$ energy expenditure in 'normally' clothed adults. British Journal of Nutrition, 1990, 63(3): 481-488.

[56] Luo M., Zhou X., Zhu Y., et al., Revisiting an overlooked parameter in thermal comfort studies, the metabolic rate. Energy \& Buildings, 2016, 118: 152-159.

[57] Wang M.N., Study on Two-node human thermal regulation model in low atmospheric pressure environment. Qingdao Technological University, Qingdao, China, 2013. (in Chinese)

[58] Cui W., Wang H., Wu T., et al., The influence of a low air pressure environment on human metabolic rate during short-term $(<2 \mathrm{~h})$ exposures. Indoor Air, 2017, 27: 282-290.

[59] Lan L., Lian Z., Liu W., et al, Investigation of gender difference in thermal comfort for Chinese people. European Journal of Applied Physiology, 2008, 102(4): 471-480.

[60] Schellen L., Loomans M.G., de Wit M.H., et al., The influence of local effects on thermal sensation under nonuniform environmental conditions--gender differences in thermophysiology, thermal comfort and productivity during convective and radiant cooling. Physiology \& Behavior, 2012, 107(2): 252-261.

[61] Wang J., Experimental research on the gender difference of thermal comfort under cabin environment. Chongqing University, Chongqing, China, 2014. (in Chinese)

[62] Mellert V., Baumann I., Freese N., et al., Impact of sound and vibration on health, travel comfort and performance of flight attendants and pilots. Aerospace Science \& Technology, 2008, 12(1): 18-25.

[63] Jan U., Vojtěch M., Linking traffic noise, noise 
annoyance and life satisfaction: a case study. International Journal of Environmental Research \& Public Health, 2013, 10(5): 1895-1915.

[64] Pennig S., Quehl J., Rolny V., Effects of aircraft cabin noise on passenger comfort. Ergonomics, 2012, 55(10): $1252-1265$.

[65] Jia S., Lai D., Kang J., et al., Evaluation of relative weights for temperature, $\mathrm{CO}_{2}$, and noise in the aircraft cabin environment. Building \& Environment, 2018, 131: 108-116.

[66] Gagge A.P., An effective temperature scale based on a simple model of human physiological regulatory response. ASHRAE Transactions, 1971, 77: 247-262.

[67] Gagge A.P., Fobelets A., Berglund L., A standard predictive index of human response to the thermal environment. ASHRAE Transactions, 1986, 92: 709-731.

[68] Liu G.D., Study on thermal comfort of human body within lower-pressure environment of asymptomatic altitude reaction. Xi'an University of Architecture and Technology, Xi'an, China, 2008. (in Chinese)

[69] Tong L., Hu S., Study on characterization of skin temperature in low pressure environment based on thermal sensation. Building Science, 2015, 2: 34-39. (in Chinese)

[70] Tanabe S., Arens E.A., Bauman F., et al., Evaluating thermal environments by using a thermal manikin with controlled skin surface temperature. ASHRAE Transactions, 1994, 100(1): 39-48.

[71] Wyon D.P., Larsson S., Forsgren B., et al., Standard procedures for assessing vehicle climate with a thermal manikin. SAE Technical Paper Series, 1989, 890049.

[72] Arens E., Zhang H., Huizenga C., Partial- and wholebody thermal sensation and comfort-Part II: Non-uniform environmental conditions. Journal of Thermal Biology, 2006, 31: 60-66.

[73] Duan M.L., The Study on Thermal Environment and Comfort for Desktop-based Task-ambient Air Conditioning. Dalian University of Technology, Dalian, China, 2007. (in Chinese)

[74] Ding Q., Jin Q., Lin D., et al., Thermal comfort study on non-uniform thermal environment with local ventilation in summer. Heating Ventilating \& Air Conditioning, 2014, 44(2): 107-113.

[75] Zhang H., Huizenga C., Arens E., et al., Thermal sensation and comfort in transient non-uniform thermal environments. European Journal of Applied Physiology, 2004, 92(6): 728-733.

[76] Wang X., Thermal comfort and sensation under transient conditions. The Royal Institute of Technology, Stockholm, Sweden, 1994.

[77] Fiala D., Lomas K.J., Stohrer M., First principles modeling of thermal sensation responses in steady-state and transient conditions. ASHRAE Transactions, 2003,
109: 179-186.

[78] Zhang H., Arens E., Huizenga C., et al., Thermal sensation and comfort models for non-uniform and transient environments: Part I: Local sensation of individual body parts. Building \& Environment, 2010, 45: 380-388.

[79] Zhang H., Arens E., Huizenga C., et al., Thermal sensation and comfort models for non-uniform and transient environments, part II: Local comfort of individual body parts. Building \& Environment, 2010, 45: 389-398.

[80] Zhang H., Arens E., Huizenga C., et al., Thermal sensation and comfort models for non-uniform and transient environments, part III: Whole-body sensation and comfort. Building \& Environment, 2010, 45: 399-410.

[81] Zhao Y., Zhang H., Arens E.A., et al., Thermal sensation and comfort models for non-uniform and transient environments, part IV: Adaptive neutral setpoints and smoothed whole-body sensation model. Building \& Environment, 2014, 72: 300-308.

[82] Zhou X., Lian Z., Lan L., An individualized human thermoregulation model for Chinese adults. Building \& Environment, 2013, 70: 257-265.

[83] Zhou X., Zhang H., Lian Z., et al., A model for predicting thermal sensation of Chinese people. Building \& Environment, 2014, 82: 237-246.

[84] Zhou X., A multi-node thermal comfort model based on Chinese thermo-biological features. Shanghai Jiao Tong University, Shanghai, China, 2015. (in Chinese)

[85] Humphreys M.A., Nicol J.F., Raja I.A., Field studies of indoor thermal comfort and the progress of the adaptive approach . Journal of Advances on Building Energy Research, 2007, 1: 55-88.

[86] Ealiwa M.A., Taki A.H., Howarth A.T., et al., An investigation into thermal comfort in the summer season of Ghadames, Libya. Building \& Environment, 2001, 36(2): 231-237.

[87] Fanger P.O., Toftum J., Thermal comfort in the future excellence and expectation. Conference Proceedings on Moving Thermal Comfort Standards into 21st Century, Windsor, UK, 2001: 11-18.

[88] Jiang Y.T., Yang C.Z., et al., Relation of sexes and thermal comfort in non-air-conditioned environment. Heating Ventilating \& Air Conditioning, 2006, 36(5): $17-21$.

[89] Cao B., Zhu Y., Ouyang Q., et al., Field study of human thermal comfort and thermal adaptability during the summer and winter in Beijing. Energy \& Buildings, 2011, 43(5): 1051-1056.

[90] Nicol J.F., Humphreys M.A., Thermal comfort as part of a self-regulating system. Building Research and Practice, 1973, 6 (3): 191-197.

[91] Brager G.S., de Dear R.J., Thermal adaptation in the built 
environment: a literature review. Energy and Buildings, 1998, 27 (1): 83-96.

[92] de Dear R., Developing an adaptive model of thermal comfort and preference. ASHRAE Transactions, 1998, 104(1): 73-81.

[93] Nicol F., Roaf S., Pioneering new indoor temperature standards: the Pakistan project. Energy \& Buildings, 1996, 23(3): 169-174.

[94] Toea D.H.C., Kubota T., Development of an adaptive thermal comfort equation for naturally ventilated buildings in hot-humid climates using ASHRAE RP-884 database. Frontiers of Architectural Research, 2013, 2(3): 278-291.

[95] Rijal H.B., Humphreys M.A., Nicol J.F., Development of the adaptive model for thermal comfort in Japanese houses. 8th Windsor Conference: Counting the Cost of Comfort in a changing world, Windsor, UK, 2014: 403-406.

[96] Singh M.K., Mahapatra S., Teller J., Development of thermal comfort models for various climatic zones of North- East India. Sustainable Cities \& Society, 2015, 14 : 133-145.

[97] Yang L., Climatic analysis techniques and architectural design strategies for bio-climatic design. Xi'an University of Architecture and Technology, Xi'an, China, 2003. (in Chinese)

[98] Zhang G., Zheng C., Yang W., et al., Thermal comfort investigation of naturally ventilated classrooms in a subtropical region. Indoor \& Built Environment, 2007, 16(2): 148-158.

[99] Mao Y., Study on climate adaptability of human beings to thermal comfort in China. Xi'an University of Architecture and Technology, Xi'an, China, 2003. (in Chinese)

[100] Yang L., Yang Q., Wang L., et al., Research on adaptive thermal comfort model for temperate area. International Conference on Building Environmental Science and Technology, Nanjing, China, 2010: 213-217.

[101] Yang D., Xiong J., Liu W., Adjustments of the adaptive thermal comfort model based on the running mean outdoor temperature for Chinese people: A case study in Changsha China. Building \& Environment, 2017, 114: 357-365.

[102] Cao B., Influence of climate and building environment on thermal adaptability of human beings. Tsinghua University, Beijing, China, 2012. (in Chinese)

[103] Yu H.R., Study on thermal comfort and thermal adaptation of human body in heating architectural environment in severe cold area. Harbin Institute of Technology, Harbin, China, 2017. (in Chinese)

[104] Pang L., Xu J., Fang L., et al., Evaluation of an improved air distribution system for aircraft cabin. Building \& Environment, 2013, 59: 145-152.
[105] Jin Y., Hu X., Zhu L., et al., Study on airflow characteristics in the semi-closed irregular narrow flow channel. Journal of Thermal science, 2016, 25(2): 123-129.

[106] Li Y.Q., Yuan S., Lai H., Numerical study of unsteady flows with cavitation in a high-speed micro centrifugal pump. Journal of Thermal Science, 2017, 26(1): 18-24.

[107] Wu C., Numerical simulation of mixing ventilation in a commercial airliner cabin. Tianjin University, Tianjin, China, 2012. (in Chinese)

[108] Zhang Y.L., Analysis of cabin thermal comfort in a civil regional aircraft. Nanjing University of Aeronautics \& Astronautics, Nanjing, China, 2014. (in Chinese)

[109] Zhang T.F., Li P.H., Zhao Y., et al., Various air distribution modes on commercial airplanes. Part 1: Experimental measurement. Hvac \& R Research. 2013, 19: 268-282.

[110] Zhang T., Chen Q., Novel air distribution systems for commercial aircraft cabins. Building \& Environment, 2007, 42: 1675-1684.

[111] Dehne T., Bosbach J., Heider A., Comparison of surface temperatures and cooling rates for different ventilation concepts in an A320 aircraft cabin under flight conditions. 13th SCANVAC International Conference on Air Distribution in Rooms and Airplane, São Paulo, Brazil, 2014: 409-414.

[112] Melikov A., Pitchurov G., Naydenov K., et al., Field study on occupant comfort and the office thermal environment in rooms with displacement ventilation. Indoor Air, 2005, 15: 205-214.

[113] Maier J., Marggraf-Micheel C., Dehne T., et al., Thermal comfort of different displacement ventilation systems in an aircraft passenger cabin. Building \& Environment, 2017, 111: 256-264.

[114] Bosbach J., Lange S., Dehne T., et al., Alternative ventilation concepts for aircraft cabins. Ceas Aeronautical Journal, 2013, 4(3): 301-313.

[115] Bosbach J., Heider A., Dehne T., et al., Evaluation of cabin displacement ventilation under flight conditions. 28th international congress of the aeronautical sciences ICAS2012, Brisbane, Australia, 2012.

[116] Zhang Y., Liu J., Pei J., et al., Performance evaluation of different air distribution systems in an aircraft cabin mockup. Aerospace Science \& Technology, 2017, 70: 359-366.

[117] Li W.J., Research on a novel personalized air distribution system for commercial aircraft cabins. Tianjin University, Tianjin, China, 2012. (in Chinese)

[118] Farag A.M., Khalil E.E., Hassan M.A., Personalized air conditioning of air craft cabins for passengers comfort and efficient energy use. 51st AIAA/SAE/ ASEE Joint Propulsion Conference, AIAA Propulsion and Energy Forum, Orlando, FL, USA, 2015, AIAA 2015-4125: $1-11$. 